\title{
Worldness Strategy: An Empirical Study on Destination Branding
}

\author{
Murat Kayak \\ University of Naples Federico II, Italy \\ murat.kayak@unina.it
}

\begin{abstract}
Global society and citizenship is possible with understanding worldness strategy in tourism. The purpose of this study is to investigate how destination brand worldness mediates the relationship between destination brand prestige and intention to revisit. Partial Least Square Structural Equation Modeling is undertaken to conduct the study. A self-administered survey is used for collecting data from Taiwanese travelers. Smart PLS 3 is used to test the structural model. Through the empirical findings, a full mediation exists. The findings are limited to Taiwanese travelers. The social classes are not investigated. Further research could implement the same model in a different country by differentiating the social classes. This study advances our understanding on how to make a destination a global brand.
\end{abstract}

Keywords: worldness, branding, intention to revisit

\section{INTRODUCTION}

Prestige is an important driver for some travellers. (e.g., Riley, 1995; Correia, \& Moital, 2009; Correia \& Kozak, 2012). For example, Correia and Kozak (2012) has aimed to test a model of prestige status seeking behaviour that is able to provide conceptual evidence of how to understand the role that prestige plays in tourists' choices, and perceiving the leading forces that motivate them to choose destinations based on the sense of achieving status. They confirmed that prestige is a multidimensional construct.

Riley (1995) concluded that the underlying dimensions of prestige-worthy leisure travel were the same across all informants' responses but instances of prestige worthy leisure travel were different in many cases (p. 645). Meanwhile, an important contribution to the literature is offered by Vigneron and Johnson (1999). They combined the concepts of existing research on prestige consumers and studies which examined entirely different aspects of consumer behaviour.

By addressing prior research, the purpose of this study is to investigate how destination brand worldness mediates the relationship between destination brand prestige and intention to revisit. Partial Least Square Structural Equation Modeling is undertaken to conduct the study. A self-administered survey is used for collecting data from Taiwanese travelers. Smart PLS 3 is used to test structural models. Through the empirical findings, a full mediation exists. The findings are limited to Taiwanese travelers. The social classes are not investigated. Further research could implement the same model in a different country by differentiating the social classes. This study advances our understanding on how to make a destination a global brand.

\section{THEORETICAL BACKGROUND}

Prestige motivation in tourism is defined as "the motivational process by which individuals strive to improve their regard or honor through the consumption of tourism experiences that confer and symbolize the prestige both for individuals and surrounding others" (Correia \& Moital, 2009, p.18). 


\section{Destination Brand Prestige}

Vigneron and Johnson (1999) classifies prestige in five categories as; perceived conspicuous value, perceived unique value, perceived social value, perceived hedonic value and perceived quality value. The definitions are derived from Vigneron and Johnson (1999) respectively below;

- The consumption of prestige brands is viewed as a signal of status and wealth, and whose price, expensive by normal standards, enhances the value of such a signal.

- If virtually everyone owns a particular brand it is by definition not prestigious.

- The role-playing aspects and the social value of prestige brands can be instrumental in the decision to buy.

- For a brand which satisfies an emotional desire such as a prestige brand, a product's subjective intangible benefits such as aesthetic appeal is clearly determining the brand selection.

- Prestige is derived partly from the technical superiority and the extreme care that takes place during the production process.

Based on the definitions above by Vigneron and Johnson (1999), a destination can be prestigious if a tourist can show his/her social status in the specific destination. Therefore, destination brand prestige might be defined as a destination that provides some tourists high-quality service that some other tourists are not able to get.

\section{Destination Brand Worldness}

Kayak and Simoni (2016) introduced destination brand worldness. Their findings indicated that destination brand worldness has a significant impact on intention to revisit. They define destination brand worldness as " $\ldots$ the positive perception that a tourist has of a destination that is visited by people from several different countries of the world" (p. 672). Then, iis meaningful to see the mediating effect of destination brand worldness between destination brand prestige and intention to revisit (Correia \& Kozak, 2012).

\section{The Research Question}

The research question is formulated as; does destination brand worldness mediate the relationship between destination brand prestige and intention to revisit?

\section{RESEARCH METHODOLOGY}

This study aims to explore the mediating effects of destination brand worldness between destination brand prestige and intention to revisit. Following methods are used to test the research hypotheses.

\section{Sample Selection and Data Collection}

This empirical study selects Taiwanese tourists as the relevant sample. There was no particular reason to select Taiwanese tourists because collecting data was convenient for the researcher. 104 participants filled in the questionnaire. The questionnaire was originally in English. The English version questionnaire is translated into Traditional Chinese to collect data.

\section{Measures}

This study adopts four-item scales for destination brand prestige from Vigneron \& Johnson (1999), adopts five-item scales for destination brand worldness from Kayak and Simoni (2016), and adopts three-item 
scales for intention to revisit from Horng et al., (2012); Kim et al., (2009). Measurement items are shown in Table 1.

Table 1. Measurement

\begin{tabular}{|l|l|l|}
\hline $\begin{array}{l}\text { Destination brand } \\
\text { worldness (DBW) }\end{array}$ & $\begin{array}{l}\text { 1) This destination is a world tourism destination } \\
\text { 2) Tourists from across the world visit this destination } \\
\text { 3) This destination hosts worldwide tourists, } \\
\text { 4) This destination is promoted all over the world } \\
\text { 5) World class people visit this destination }\end{array}$ & $\begin{array}{l}\text { (Kayak \& Simoni, } \\
\text { 2016) }\end{array}$ \\
\hline $\begin{array}{l}\text { Destination brand } \\
\text { prestige (DBP) }\end{array}$ & $\begin{array}{l}\text { 1) This destination is a prestigious destination. } \\
\text { 2) Visiting this destination shows my social status. } \\
\text { 3) This destination is a symbol of prestige. } \\
\text { 4) The appeal of this destination is impressive. }\end{array}$ & $\begin{array}{l}\text { (Vigneron \& } \\
\text { Johnson, 1999) }\end{array}$ \\
\hline $\begin{array}{l}\text { Intention to revisit } \\
\text { (TI) }\end{array}$ & $\begin{array}{l}\text { 1) I might visit this destination again. } \\
\text { 3) I wish to visit this destination again. }\end{array}$ & $\begin{array}{l}\text { (Horng et al., 2012; } \\
\text { Kim et al., 2009). }\end{array}$ \\
\hline
\end{tabular}

\section{Data Analysis}

Data screening procedures were examined in SPSS. Normality was evaluated through calculation of the mean, standard deviations, skewness and kurtosis (Tabachnick \& Fidell, 2001). Then, an exploratory factor analysis is conducted with promax rotation. The reason is because constructs are correlated (Hair et al., 2010). Next, common method variance was examined because a single survey method was used to measure independent and dependent variables (Lindell \& Whitney, 2001). Finally, the theoretical model was implemented using SmartPLS 3.0. SmartPLS is a structural equation modeling (SEM) package based on the partial least squares (PLS) method of assessing a measurement model and a structural model. PLS-SEM is a powerful method for identifying key driver constructs in small samples (Hair, Ringle, \& Sarstedt, 2011), which fits the aim of this research, which uses a small sample to analyze a new specific latent variable, perceived destination worldness, as a predictor for intention to revisit.

\section{Testing A Mediator With Bootstrapping in PLS-SEM}

Mediating effect involves a third variable that plays an intermediate role in the relationship between the independent and dependent variable. That means, the effect of the independent variable $X$ on the dependent variable $\mathrm{Y}$ is mediated by a third variable, $\mathrm{M}$, called the mediation variable or mediator (Baron \& Kenny, 1986). Over the last few decades, most of the researchers have followed Baron and Kenny (1986) approach for testing mediating effects however over the past few years, Baron and Kenny (1986) approach for determining mediating effects has been challenged by scholars such as Preacher and Hayes (2004; 2008), and Zhao et al. (2010). Preacher and Hayes $(2004 ; 2008)$ show that the Sobel test is not appropriate for analyzing indirect effects. This bias is especially relevant for small sample sizes, which is often the case in PLS-SEM (Shrout \& Bolger, 2002). Alternatively, In PLS-SEM, researchers can apply a bootstrapping approach to test the significance of the indirect effect among the variables (Sarstedt, et al., 2014). The bootstrapping procedure is a non-parametric inferential technique that randomly draws several subsamples (e.g., 5,000) with replacement from the original dataset (Sarstedt, et al., 2014). Finally, bootstrapping procedures are used by re-sampling 5000 times and using the percentile method to make 95\% confidence intervals (Zhao et al., 2010). 


\section{RESULTS}

\section{Data Screening}

There were more females $(69.8 \%)$ than male $(30.2 \%)$. In the questionnaire, there were no missing values because all the questions were required to fill. In order to assess the normality, possible outliers were analyzed by calculating the $\mathrm{z}$ value An absolute value 2.58 was appropriate based on the sample size (Tabachnick \& Fidell, 2001). Detected outliers deleted and reduced the sample size to 87. Means and standard deviations of the individual item shown in Table 2 . The results indicate that response variability was satisfactory because as seen in Table 2, standard deviations for the individual items are greater than or close to $+1.00,-1.00$. The items were in the adequate levels. Furthermore, skewness, and kurtosis for each item are tested and all is appropriate as shown in Table 2.

Table 2. Mean, Standard Deviation, Skewness and Kurtosis

\begin{tabular}{|l|l|l|l|l|}
\hline Items & Mean & Std. Deviation & Skewness & Kurtosis \\
\hline DBW_1 & 5.66 & 1.098 & -.461 & -.909 \\
\hline DBW_2 & 5.80 & 1.055 & -.449 & -.989 \\
\hline DBW_3 & 5.39 & 1.038 & .044 & -1.170 \\
\hline DBW_4 & 5.61 & 1.038 & -.107 & -1.142 \\
\hline DBW_5 & 5.47 & 1.109 & -.083 & -1.144 \\
\hline DBP_1 & 5.57 & 1.063 & -.259 & -.690 \\
\hline DBP_2 & 4.64 & 1.161 & .189 & .025 \\
\hline DBP_3 & 4.68 & 1.146 & .095 & -.028 \\
\hline DBP_4 & 5.82 & .922 & -.352 & -.688 \\
\hline TI_1 & 6.00 & 1.057 & -.605 & -.946 \\
\hline TI_2 & 6.05 & .987 & -.687 & -.625 \\
\hline TI_3 & 5.82 & 1.084 & -.408 & -1.128 \\
\hline
\end{tabular}

\section{Exploratory Factor Analysis}

After the data screening procedure, 87 data were valid. An exploratory factor analysis was conducted with promax rotation. The reason for using promax rotation was because constructs are correlated. The Kaiser-Meyer-Olkin statistic of 0.825 indicates that the data are appropriate for factor analysis. 2 factors emerged and the test is employed once again with a fixed number of 3 factors to extract. The test was appropriate however 2 items were removed based on cross loadings, coded as DBP_1 and DBP_4. All the items were cleanly and separately loaded onto the corresponding factors, representing destination brand prestige, destination brand worldness and intention to revisit, as shown in Table 3. 
Table 3: Exploratory Factor Analysis

\begin{tabular}{|l|l|l|l|}
\hline Items & Worldness & Prestige & Travel Intention \\
\hline DBW_1 & $\mathbf{. 7 9 7}$ & -.147 & .118 \\
\hline DBW_2 & $\mathbf{. 8 1 3}$ & -.085 & .125 \\
\hline DBW_3 & $\mathbf{. 8 6 3}$ & -.025 & -.091 \\
\hline DBW_4 & $\mathbf{. 7 3 1}$ & .116 & -.013 \\
\hline DBW_5 & $\mathbf{. 6 0 2}$ & .288 & .007 \\
\hline DBP_2 & -.066 & $\mathbf{. 8 1 8}$ & .080 \\
\hline DBP_3 & .039 & $\mathbf{. 9 7 5}$ & -.044 \\
\hline TI_1 & .129 & -.035 & $\mathbf{. 8 2 8}$ \\
\hline TI_2 & -.010 & .022 & $\mathbf{. 9 7 6}$ \\
\hline TI_3 & -.044 & .051 & $\mathbf{. 8 9 8}$ \\
\hline
\end{tabular}

\section{Validity and Reliability of the Measurement Model}

The measurement model was tested for reliability and validity using SmartPLS 3.0. Composite reliability (CR) and average variance explained (AVE) of destination brand prestige, destination brand worldness, and travel intention are shown in Table 4. The composite reliability for destination brand prestige, destination brand worldness, and intention to revisit were greater than 0.80, and the AVE was higher than 0.50 , indicating strong reliability and convergent validity, respectively.

Table 4: Cronbach's Alpha, Composite Reliability, and Average Variance Extracted

\begin{tabular}{|l|l|l|l|}
\hline Constructs & Cronbach's Alpha & Composite Reliability & AVE \\
\hline Prestige & 0.891 & 0.948 & 0.897 \\
\hline Worldness & 0.891 & 0.920 & 0.902 \\
\hline Revisit & 0.943 & 0.963 & 0.697 \\
\hline
\end{tabular}

Table 5 presents the ratio of the square root of the AVE of each reflective latent variables. The diagonal elements in parentheses are the correlations of each construct with its own measure, which is the square root of the AVE. When computing square root of AVE, prestige, worldness, and revisit are; 0.897, 0902, and 0.697 respectively. Off-diagonal elements include correlations between constructs. Diagonal elements should be larger than the entries in the corresponding rows and columns for adequate discriminant validity. Clearly, each construct is more highly correlated with its own measure than with any other constructs, indicating strong discriminant validity under the Fornell-Larcker criterion (Fornell \& Larcker, 1981).

Table 5: Correlations of the latent variables and the square root of AVE

\begin{tabular}{|l|l|l|l|}
\hline Latent variable & DBP & DBW & TI \\
\hline Destination brand prestige & $(0.949)$ & & \\
\hline Destination brand worldness & 0.347 & $(0.835)$ & \\
\hline Travel intention & 0.220 & 0.659 & $(0.947)$ \\
\hline
\end{tabular}


In addition, the loadings and cross-loadings of the items compared across destination brand prestige, destination brand worldness and intention to revisit variables show strong convergent validity with high loadings scores as all higher than 0.7 .

\section{Common Method Variance and Theoretical Model Validation}

Although the items were specifically developed by reviewing the relevant literature, age was also included as a marker variable to check common method bias. Age is chosen because it is theoretically an unrelated construct (Lindell \& Whitney, 2001). Starting from this point of view, age was tested as a marker variable in SPSS. The findings showed that age has no significant correlation with the destination brand prestige, destination brand worldness and intention to revisit variables. In other words, this is the evidence for discriminant validity that common method variance does not significantly affect the relationship among the study variables.

\section{Mediation Test}

Fig. 1 summarizes the result of the structural model test. Bootstrapping procedures pre-sampled 5000 times, and percentile method $95 \%$ confidence intervals are used to test the mediator effects of destination brand worldness between destination brand prestige and intention to revisit (Zhao et al., 2010). The results showed that destination brand worldness has a competitive mediation effect between destination brand worldness and intention to revisit (indirect effect: $\beta=0.230$ ) at the $p$ value; $p<0.001$, indicating full mediation because the path from destination brand prestige to intention to revisit is insignificant in bootstrapping procedure. The path coefficient of destination brand prestige to the intention to revisit $(\beta=-0.009)$ is rejected because $p$ value; $p<0.926$. The path coefficient of destination brand prestige to destination brand worldness, and destination brand worldness to intention to revisit $(\beta=0.347 ; \beta=0.662)$ are significant and accepted at the $\mathrm{p}$ value as $\mathrm{p}<0.001$. In the structural model, destination brand prestige together with destination brand worldness explain $\% 43$ of the variance in intention to revisit whereas destination brand prestige explain $\% 12$ of the variance in destination brand worldness.

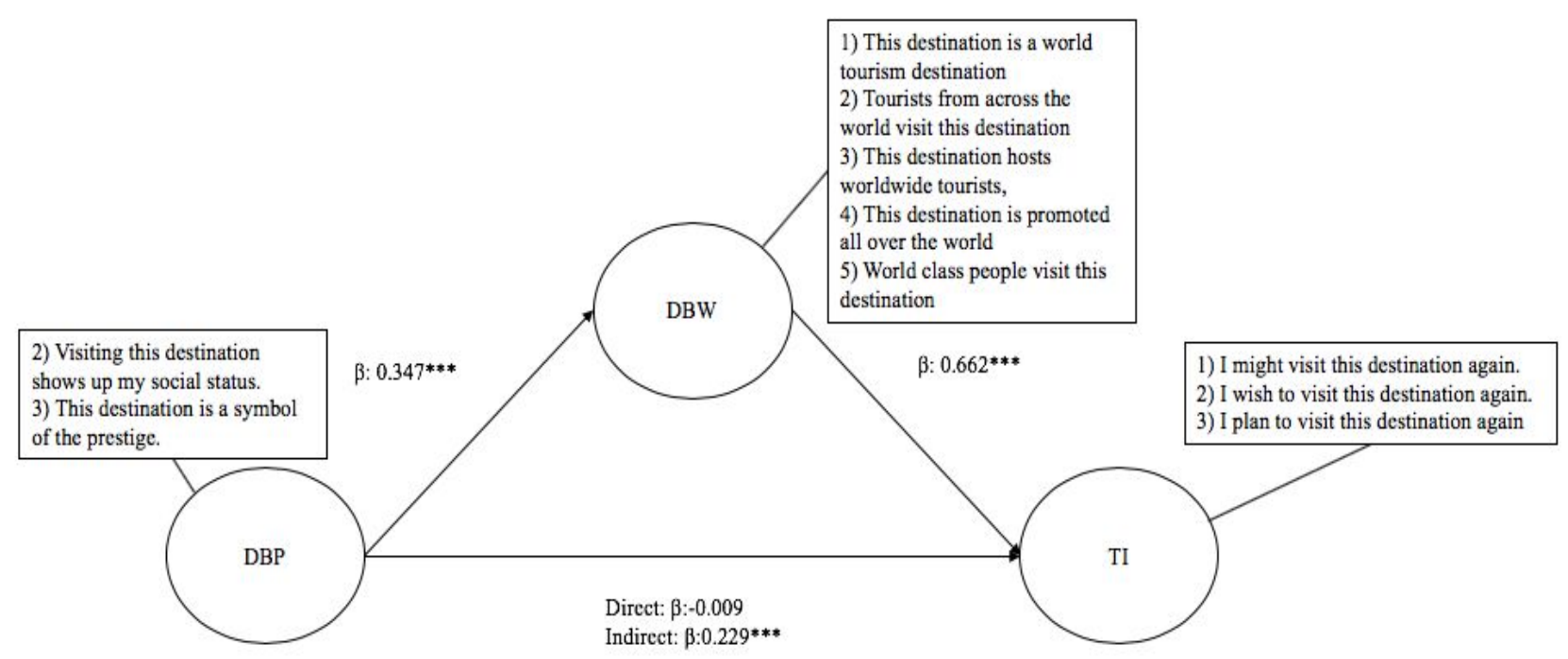




\section{CONCLUSIONS}

Global society and citizenship is possible with understanding worldness strategy in tourism. The purpose of this study was to investigate how destination brand worldness mediates the relationship between destination brand prestige and intention to revisit. Partial Least Square Structural Equation Modeling was undertaken to conduct the study. A self-administered survey was used for collecting data from Taiwanese travelers. Smart PLS 3 is used to test the structural model. Through the empirical findings, a full mediation exists. This study advances our understanding on how to make a destination a global brand. Building a brand for a product and for destination is different. A product-based brand is a global brand if the brand is located in multiple countries. For example; a smartphone is a product that can be moved from one country to another. However; a destination as a product can not move to any other country. Then; how can we build a global brand for a destination? This study advances prior study (Kayak \& Simoni, 2016) by investigating the mediating effect of destination brand worldness. Destination practitioners could formulate and implement worldness strategies in their destinations to attract more travelers.

This study shows that there is no direct relationship from destination brand prestige and intention to revisit (Riley, 1995; Correia, \& Moital, 2009; Correia \& Kozak, 2012). Destination brand prestige is an important driver if a destination represents global travelers.

\section{Limitation and Study Forward}

The findings are limited to Taiwanese travelers. The social classes are not investigated. Further research could implement the same model in a different country by differentiating the social classes.

\section{ACKNOWLEDGMENT}

Authors would like to thank the University of Naples Federico II for the support. Methodology is developed based on the Ph.D. Dissertation submitted and presented at the University of Naples Federico II.

\section{REFERENCES}

Baron, R. M., \& Kenny, D. A. (1986). The moderator-mediator variable distinction in social psychological research: Conceptual, strategic, and statistical considerations. Journal of personality and social psychology, 51(6), 1173.

Correia, A., \& Kozak, M. (2012). Exploring prestige and status on domestic destinations: The case of Algarve. Annals of Tourism Research, 39(4), 1951-1967.

Fornell, C., \& Larcker, D. F. (1981). Evaluating structural equation models with unobservable variables and measurement error. Journal of marketing research, 18(1), 39-50.

Hair, J. F., Black, W. C., Babin, B. J., \& Anderson, R. E. (2009). Multivariate Data Analysis $7^{\text {th }}$ Edition Pearson Prentice Hall.

Hair, J. F., Ringle, C. M., \& Sarstedt, M. (2011). PLS-SEM: Indeed a silver bullet. Journal of Marketing theory and Practice, 19(2), 139-152.

Kayak, M., \& Simoni, M. (2016). Revisiting tourist behavior via destination brand worldness. Management Science Letters, 6(11), 671-680.

Kim, T. T., Kim, W. G., \& Kim, H. B. (2009). The effects of perceived justice on recovery satisfaction, trust, word-of-mouth, and revisit intention in upscale hotels. Tourism management, 30(1), 51-62. 
Preacher, K. J., \& Hayes, A. F. (2004). SPSS and SAS procedures for estimating indirect effects in simple mediation models. Behavior research methods, instruments, \& computers, 36(4), 717-731.

Preacher, K. J., \& Hayes, A. F. (2008). Asymptotic and resampling strategies for assessing and comparing indirect effects in multiple mediator models. Behavior research methods, 40(3), 879-891.

Sarstedt, M., Ringle, C. M., Smith, D., Reams, R., \& Hair Jr, J. F. (2014). Partial least squares structural equation modeling (PLS-SEM): A useful tool for family business researchers. Journal of Family Business Strategy, 5(1), 105-115.

Shrout, P. E., \& Bolger, N. (2002). Mediation in experimental and nonexperimental studies: new procedures and recommendations. Psychological methods, 7(4), 422.

Tabachnick, B. G., Fidell, L. S., \& Ullman, J. B. (2007). Using multivariate statistics. Boston, MA: Pearson.

Vigneron, F., \& Johnson, L. W. (1999). A review and a conceptual framework of prestige-seeking consumer behavior. Academy of marketing science review, 1(1), 1-15.

Zhao, X., Lynch Jr, J. G., \& Chen, Q. (2010). Reconsidering Baron and Kenny: Myths and truths about mediation analysis. Journal of consumer research, 37(2), 197-206. 